ART IKEL

E-ISSN: $2615-5028$

\title{
GERAKAN FAJAR NUSANTARA (GAFATAR): KRISIS IDEOLOGI DAN ANCAMAN KEBANGSAAN
}

\author{
Muhammad Wildan
}

(UIN Sunan Kalijaga, Yogyakarta, Indonesia; wildan71@gmail.com)

\begin{abstract}
The Fajar Nusantara Movement (Gafatar) is an interesting phenomenon in the contemporary era of Indonesia. In the midst of growing rationality and the growth of the world's mainstream religions, Gafatar was born as a new 'religion'. This article discusses Gafatar as a new form of ideology that was born as a result of the ideological crisis experienced by post-Reformation Indonesians. This paper seeks to trace the history of development and the Gafatar teachings used by this organization to recruit new members. Historically, this research was carried out by reviewing existing books and articles and supported by news in the mass media with the perspective of the messianic movement. This article sees that Gafatar is a reincarnation of the Al-Qiyadah Al-Islamiyah and Komar movements in which Ahmad Musaddeg is the central figure. The main factor in the spread of the Gafatar ideology was people's disappointment with Indonesia's economic and political conditions. This is also supported by the ideological crisis factors experienced by some Indonesian people and the weak religious understanding and thirst for spirituality among the middle class. Finally, this article also sees that it is possible to emerge similar movements, so that humanist conflict resolution is needed in order to deal with Gafatar and the schools with certain ideologies that are different from the ideology of the state in the future.
\end{abstract}

Keywords: New religion; Messianic movement; Ideological crisis; Nationality

\begin{abstract}
Abstrak
Gerakan Fajar Nusantara (Gafatar) merupakan fenomena menarik di era kontemporer Indonesia. Di tengah berkembangnya rasionalistas dan tumbuhnya agama-agama mainstream dunia, Gafatar lahir sebagai sebuah 'agama' baru. Artikel ini membahas Gafatar sebagai bentuk ideologi baru yang lahir akibat krisis ideologi yang dialami bangsa Indonesia pasca Reformasi. Tulisan ini berusaha untuk menelusuri sejarah perkembangan dan ajaran-ajaran Gafatar yang digunakan oleh organisasi ini untuk merekrut anggota baru. Secara historis, penelitian ini dilakukan dengan mengkaji buku-buku dan artikel yang sudah ada dan didukung oleh pemberitaan di media massa dengan perspektif gerakan mesianis. Artikel ini melihat bahwa Gafatar merupakan reinkarnasi dari gerakan Al-Qiyadah Al-Islamiyah dan Komar di mana Ahmad Musaddeq sebagai tokoh sentralnya. Faktor utama merebaknya ideologi Gafatar adalah kekecewaan msyarakat terhadap kondisi ekonomi dan politik Indonesia. Hal itu juga didukung oleh faktor krisis ideologi yang dialami oleh sebagian masyarakat Indonesia dan lemahnya pemahaman keagamaan serta kehausan spiritualitas di kalangan kelas menengah. Terakhir, artikel ini juga melihat bahwa dimungkinkan akan muncul gerakan-gerakan sejenis, sehingga diperlukan resolusi konflik yang humanis dalam
\end{abstract}


rangka menangani Gafatar dan aliran-aliran dengan ideologi tertentu yang berbeda dengan ideologi negara di masa depan.

\section{Kata Kunci: Agama baru; Gerakan mesianis; Krisis Ideologi; Kebangsaan}

\section{A. PENDAHULUAN}

Gerakan Fajar Nusantara (Gafatar) mulai ramai dibicarakan publik setelah hilangnya dr. Rica Tri Handayani dan anaknya sejak 30 Desember 2015. Ditemukannya dr. Rica di Pangkalan Bun, Kalimantan Tengah, membuka tabir kasus hilangnya ratusan bahkan ribuan orang yang hampir semua terkait dengan gerakan Gafatar. Sejumlah media mengungkap fakta mengenai adanya base camp Gafatar di Mempawah, Kalimantan Tengah, sebagai tempat hijrah anggota organisasi ini. ${ }^{1}$

Munculnya Gafatar di Indonesia dapat dibaca sebagai fenomena gejolak ideologi dari sekelompok orang yang membentuk suatu komunitas dengan mengembangkan ideologi baru yang bertentangan dengan ideologi Pancasila. Secara historis, kehadiran Gafatar ini hampir mirip dengan kemunculan sejumlah gerakan serupa seperti gerakan Negara Islam Indonesia (NII) ${ }^{2}$, al-Qiyadah al-Islamiyah ${ }^{3}$, Komunitas

\footnotetext{
Sejumlah berita di media terutama media daring antara lain https://www.liputan6.com/news/read/2416885/5-fakta-gafatar-yang-penting-diketahui; https://www.bbc.com/indonesia/indonesia-43504606; https://www.tifafoundation.org/gafatar-danpemiskinan-oleh-negara/

${ }^{2}$ Negara Islam Indonesia (NII) atau lebih dikenal dengan nama Darul Islam (DI) adalah sebuah gerakan politik yang diproklamirkan pada tanggal 7 Agustus 1949 oleh Sekarmadji Maridjan Kartosuwirjo di desa Cisampah, Ciawiligar, Cisayong, Tasikmalaya, Jawa Barat. Gerakan ini bertujuan menjadikan Indonesia sebagai negara teokrasi, yaitu Islam dan menjadikan syari’at Islam sebagai undangundangnya.
}

3 Al-Qiyadah Al-Islamiyah didirikan oleh Ahmad Mushadeq pada tahun 2000. Mushadeq dibaiat menjadi anggota NII pada 1987. Namun, karena terjadi ketidakcocokan dengan NII KWIX pimpinan Panji Gumilang, Mushadeq mendirikan Al-Qiyadah. Gerakan ini bertujuan memurnikan ajaran Nabi Musa, Isa, dan Muhammad. Sebelum dilarang MUI pada 2007, gerakan ini memiliki 8.000 
Millah Abraham (Komar) ${ }^{4}$, dan gerakan lainnya. Beberapa gerakan tersebut muncul dari beragam faktor mulai dari ketidakpuasan sekelompok orang terhadap terhadap ideologi mainstream, baik yang berasal dari agama maupun negara, kesejahteraan (faktor ekonomi), dan pemenuhan kebutuhan spiritual di tengah kehidupan modern. Beberapa faktor tersebut kiranya cukup relevan untuk melihat dinamika Gafatar dalam tulisan ini.

Menurut Al Makin, setidaknya terdapat dua faktor historis berikut memberikan dorongan munculnya gerakan seperti Gafatar dan lainnya di Indonesia pasca-kolonial. Pertama, gerakan kenabian milenarisme dan mesianisme yang mengajarkan faham reinkarnasi, pembaruan spiritual, ratu adil, dan erucakra (penyelamat). Kedua, 'agama populer' seperti Malim (diinspirasi oleh tokoh kharismatik Si Singamangaraja XII) yang mengkombinasikan berbagai unsur tradisi agama di dunia seperti Islam, Kristen, dan kepercayaan setempat. ${ }^{5}$ Dalam konteks Gafatar, setidaknya gerakan ini mewarisi kedua model tersebut sebagaimana akan dibahas pada sub-bahasan berikutnya.

Dalam sudut pandang sosiologi agama, Gafatar merupakan bagian dari New Religious Movement, gerakan keagamaan baru yang muncul sebagai gerakan non-arus utama agama besar dunia, dalam hal ini Islam. Munculnya new religious movement biasanya diilhami oleh individu kharismatik tertentu sebagaimana yang terjadi dalam gerakan serupa lainnya seperti Ron Hubbard (scientology), Moses David (Cbildren of God or the Family), John Wimber (vineyard Christian Fellowship), dan Maharishi (transcendental

pengikut orang dari berbagai daerah seperti Jakarta, Bandung, Yogyakarta, Surabaya, Padang, Makassar, dan Kalimantan Selatan.

4 Komar merupakan kelanjutan dari Al-Qiyadah Al-Islamiyah setelah organisasi ini diakui sebagai organisasi sesat oleh pemerintah. Komar juga ditengarai sebagai embrio lahirnya Gafatar.

${ }^{5}$ Al Makin, Nabi-Nabi Nusantara: Kisah Lia Eden dan Lainnya (Yogyakarta: Suka Press, 2017), hlm. 6 . 
mediation). ${ }^{6}$ Beberapa faktor sebagai pemicu munculnya gerakan ini setidaknya adalah sebagai berikut: Pertama, resistensi (penolakan) masyarakat modern yang menganut materialisme, utilitarianisme, individualisme, dan rasionalisme yang mendominasi kebudayaan masyarakat; Kedua, kehidupan modern yang berporos pada individualisme yang secara perlahan menghilangkan pandangan hidup tradisional dalam masyarakat; Ketiga, stagnasi agama atau aliran ketuhanan dalam memberikan jawaban atau respons atas kehidupan modern; Keempat, terbuka terhadap gagasan dan cara pemikiran baru; Kelima, adanya kekecewaan atau keprihatinan terhadap sistem sosial modern dan kehidupan urban yang impersonal atau individualistik. Dalam hal ini, kebutuhan terhadap spiritualitas dalam bentuk gerakan baru menjadi salah satu kebutuhan mendesak manusia terutama yang hidup di lingkungan urban. ${ }^{7}$

Fenomena munculnya Gafatar ini menimbulkan beberapa pertanyaan penting: mengapa Gafatar bisa muncul hingga menimbulkan keresahan di masyarakat dengan ideologi dan ajarannya? Adakah keterkaitan maupun kesamaan pola antara Gafatar dengan gerakan-gerakan serupa yang pernah muncul di Indonesia dan dianggap sesat? Benarkah anggapan bahwa Gafatarmerupakan sebuah gerakan sistematis yang memiliki kecenderungan berusaha untuk membentuk komunitas baru yang pada akhirnya menjurus kepada disintegrasi bangsa dan mengancam kedaulatan NKRI? Dengan menjawab beberapa pertanyaan tersebut diharapkan tulisan ini dapat menjadi rujukan untuk mengambil langkah yang tepat guna menanggulangi hal-hal yang mengancam kedaulatan NKRI, sekaligus agar gerakan menyimpang yang serupa tidak muncul kembali di kemudian hari. Data dalam tulisan ini diambil dengan melakukan studi

${ }^{6}$. Moch. Rosyid, "Tanggung Jawab Pemerintah Daerah terhadap Eks-Anggota Gerakan Fajar Nusantara", Jurnal Sejarah Citra Lekha, Vol. 2 , No. 2, 2017, hlm. 92-111.

${ }^{7}$ Ibid. 
pustaka, yaitu dengan mengumpulkan berbagai sumber tulisan baik dari hasil penelitian, buku, tulisan jurnal, dan sejumlah pemberitaan di media daring atau internet terkait Gafatar. Adapun analisis yang digunakan adalah deskriptif kualitatif untuk menggambarkan dinamika Gafatar dalam kehidupan Indonesia khususnya Pasca Reformasi.

\section{B. METODE}

Objek penelitian ini didasarkan pada paradigma metode penelitian kualitatif dengan analisis deduktif. Pendekatan penelitian ini dipilih karena penelitian kualitatif dengan metode tersebut adalah pendekatan penelitian yang mencakup penggalian materi pelajaran secara mendalam (Denzin dan Lincoln, 1994: 66). Tujuan dari penelitian kualitatif adalah untuk memahami keadaan, peristiwa, kelompok, atau interaksi sosial tertentu (Locke, Spirduso, \& Silverman, 1987). Studi ini dapat ditafsirkan sebagai proses investigasi di mana para peneliti secara bertahap memahami fenomena sosial dengan membedakan, membandingkan, mereproduksi, membuat katalog, dan mengklasifikasikan objek penelitian (Miles \& Huberman, 1994). Marshall dan Rossman (1989) mengatakan bahwa penelitian seperti ini melibatkan peneliti untuk mempelajari pengaturan alamiah.

Demikian sehingga peneliti memasuki dunia informan melalui interaksi berkelanjutan, mencari makna dan perspektif informan, yang dalam hal ini adalah para aktivis Gafatar. 


\section{HASIL DAN PEMBAHASAN}

\section{Kemunculan Gafatar}

Sebenarnya, Gafatar merupakan organisasi kemasyarakatan (ormas) yang legal. Organisasi ini diprakarsai dan didirikan oleh 51 orang pada 14 Agustus 2011, dan kemudian dideklarasikan pada 21 Januari 2012 di Jakarta. Deklarasi Gafatar tersebut diikuti oleh 14 Dewan Pimpinan Daerah (14 Provinsi) dengan Ketua Umum Mahful Muis Tumanurung. Gafatar mengklaim memiliki pengurus di 34 provinsi seluruh Indonesia. ${ }^{8}$ Di dalam akta pendiriannya, Gafatar tercatat sebagai ormas berasaskan Pancasila dan legalitas pendiriannya terdapat dalam UUD 1945 Pasal 28, UU No.8 1985 tentang Ormas dan akte pendirian ormas No.1 tanggal 05 September 2011.

Salah satu hal yang mencuri perhatian publik tentang Gafatar adalah munculnya nama Ahmad Musaddeq sebagai tokoh sentral organisasi ini. Hal inilah yang menimbulkan opini bahwa Gafatar tidak lain merupakan reinkarnasi dari gerakangerakan serupa yang pernah didirikan oleh Musaddeq. ${ }^{9}$ Sebagaimana diketahui bahwa Musaddeq adalah pendiri al-Qiyadah al-Islamiyah dan menobatkan dirinya sebagai nabi. Al-Qiyadah al-Islamiyah sendiri berdiri pada tahun 2000 setelah Musaddeq keluar dari kelompok Negara Islam Indonesia Komandemen Wilayah IX (NII KW-IX) pimpinan Panji Gumilang alias Abu Toto. Musaddeq pernah bergabung dengan NII KW-IX di era 1990-an dan sejak saat itu mulai bersentuhan dengan aliran Islam Isa Bugis yang diajarkan oleh Karim Hasan, salah satu petinggi NII. ${ }^{10}$ Namun, keberadaan

\footnotetext{
8 https://m.tempo.co/read/news/2016/01/14/173735906/sejarah-lahirnya-gafatar-darimushadeq-ke-mushadeq-lagi (diakses 27 Januari 2016).

${ }^{9}$ Ahmad Musaddeq dilahirkan di Jakarta dan merupakan pensiunan Pegawai Pemerintah Provinsi DKI. Dia menjadi terkenal sejak bergabung dengan NII di era 1990-an.

${ }^{10}$ Aliran Islam Isa Bugis sebenarnya sudah dinyatakan sesat oleh Pemerintah pada tahun 1996.
} 


\section{ART IKEL}

Musaddeq di NII KW-IX tidak berlangsung lama, karena pada awal 2000 terjadi perpecahan antara Ahmad Musaddeq dengan Panji Gumilang. Musaddeq dan pengikutnya memilih keluar dari NII KW-IX dan mendirikan al-Qiyadah al-Islamiyah dengan tetap membawa dan mngajarkan doktrin ajaran Isa Bugis.

Dalam gerakannya, dakwah Al-Qiyadah al-Islamiyah yang menyerupai polapola yang pernah dilakukan NII. Perekrutan anggota dilakukan secara sembunyisembunyi yakni melalui diskusi dan indoktrinasi (cuci otak) kepada calon anggota baru. ${ }^{11}$ Perekrutan menggunakan pola ini terus dilakukan oleh Musaddeq hingga ia mendirikan Komunitas Millah Abraham (Komar). Adapun ajaran Isa Bugis yang dibawa oleh Musaddeq memiliki ajaran bahwa Islam harus dipahamidengan tolakukur rasio semata. Meskipun mengaku sebagai Islam, ajaran Isa Bugis mendoktrin pengikutnya bahwa rukun Islam seperti salat lima waktu, zakat, haji dan puasa Ramadhan tidak wajib untuk dilaksanakan. Mereka menganggap bahwa salat lima waktu belum perlu dilaksanakan karena saat ini masih seperti dakwah Islam periode Makkah. Isa Bugis juga memandang bahwa orang-orang diluarkelompok mereka adalah kafir. Selain itu, Kelompok ini juga memiliki sebuah lembaga kerasulan yang disebut lembaga rasul kolektif yang menjalankan fungsi seperti rasul atau nabi yang terdiri dari orang-orang internal kelompok ini. ${ }^{12}$

Pada tahun 2006, nama Ahmad Musaddeq semakin populer setelah mengklaim dirinya sebagai seorang nabi sekaligus sebagai Imam Mahdi bergelar al-Masih al-

\footnotetext{
Akan tetapi mereka terus menyebarkan ajaran paham ideologinya secara sembunyi-sembunyi. ajaran Islam Isa Bugis dibawa oleh seorang pria kelahiran Aceh yang bernama Muhammad Isa Bugis.

11 Robi Sugara, "Rehabilitasi Korban: Belajar dari Mantan Aktivis NII, Gafatar, dan Deportan/Returni ISIS" Convey Report Vol. 1 No. 6 2018, hlm. 18.

12 Lihat misalnya https://news.detik.com/berita/3118031/lembaga-kerosulan-isa-bugis-dannii-yang-berevolusi-menjadi-gafatar, (diakses 21 November 2018).
} 
Mau'ud. ${ }^{13}$ Setelah itu, Musaddeq mulai menyebarkan ajarannya di sekitar kediamannya di daerah DKI Jakarta dan sebagian wilayah Bekasi, Depok, dan Bogor, sebelum akhirnya berurusan dengan kepolisian. Musaddeq dijerat dengan Pasal 156 huruf (a) KUHP tentang penistaan agama ${ }^{14}$ dan divonis empat tahun penjara pada 2008. Terkait dengan hal ini, pada 3 Oktober 2007 MUI mengeluarkan fatwa sesat terhadap ajaran yang dibawa oleh Musaddeq (al-Qiyadah al-Islamiyah) ${ }^{5}$ karena dianggap melakukan sinkretisme dengan mencampurkan antara ajaran Islam, Kristen, dan Yahudi.

\section{Gafatar sebagai Ormas}

Tercatatnya Gafatar sebagai ormas dapat dilacak dan dibuktikan kebenarannya di sejumlah daerah di Indonesia. Kepala kantor Kesatuan Bangsa dan Politik (Kesbangpol) Pemerintah Provinsi DKI Jakarta menyatakan bahwa SKT Gafatar sudah ada sejak tahun 2011 dan berlaku hingga 2016. ${ }^{15}$ Pada November 2011 Gafatar tercatat sebagai ormas di Kesbangpol Kabupaten Bantul, DIY, dan pernah mendirikan kantor di Kecamatan Bangunjiwo. ${ }^{16}$ Pada bulan Desember 2011, hal yang sama juga terjadi di Kesbangpolpemerintah kotaSurakarta dibuktikan dengan diterbitkannya SKT

13 Abdus Salam atau lebih dikenal dengan Ahmad Musaddeq sebelumnya bertapa demi mendapatkan di sebuah gua bernama Gua Bunder di kawasan Gunung Bunder di Bogor, Jawa Barat. Ia bertapa selama 40 hari 40 malam mendapatkan kepastian agar bisa menjadi rasul Allah menggantikan kepemimpinan Nabi Muhammad, hingga akhirnya pada 23 Juli 2006 ia mengaku sebagai nabi. Gatra, Metamorfosis Gafatar, edisi 27 Januari 2016, hlm.16-17.

14 Gatra, Metamorfosis Gafatar, edisi 27 Januari 2016, hlm. 16-17.

${ }^{15}$ Kepala Kesbangpol DKI, Ratiyono, menyatakan bahwa setiap ormas yang terdaftar di DKI memiliki SKT yang belaku selama lima tahun. Artinya Gafatar pun yang terdaftar sebagai ormas di DKI sejak 2011 memiliki SKT yang belaku hingga 2016 sesuai masa berlaku SKT di DKI yang berlaku selama lima tahun sejak terdaftar. http://www.cnnindonesia.com/nasional/20160113090937-12-103911/gafatarpernah-terdaftar-sebagai- ormas-di-jakarta-pada-2011/ (diakses 2 Februari 2016)

16 Menurut kepala Kesbangpol Bantul, Sumasriana, menyatakan bahwa Gafatar pernah terdaftar sebagai ormas di Bantul pada November 2011 hingga pada tahun 2012 terbit Surat Edaran dari Kementerian Dalam Negeri yang menginstruksikan agar tidak menanggapi Gafatar sebagai ormas. http://www.antaranews.com/berita/539746/gafatar-pernah-terdaftar-sebagai-organisasi-massa-di-bantul (diakses 6 Februari 2016). 
kantor Kesbangpol Pemkot Surakarta Nomor 220/XII/2011 tertanggal 20 Desember 2011. ${ }^{17}$ Meskipun demikian, Pemkot Surakarta menyatakan bahwa SKT Gafatar telah berakhir pada 2014. Selanjutnya, pada 2012 Gafatar tercatata juga di sejumlah daerah lainnya seperti di Banyumas ${ }^{18}$ dan Kota Balikpapan, Kalimantan Timur. ${ }^{19}$

Hal di atas menjadi dilema bagi pemerintah pusat dan pemerintah daerah. DI satu sisi, Gafatar sudah terdaftar sebagai ormas di beberapa daerah, tetapi di sisi lain,ternyata Kementerian Dalam Negeri (Kemendagri) tidak mengakui Gafatar. Kemendagri menganggap bahwa Gafatar telah menyalahi aturan sebagai organiasasi masyarakat maupun organisasi keagamaan. ${ }^{20}$ Kemendagri pada tahun 2012 secara resmi mengeluarkan pernyataan menolak mengakui Gafatar sebagai ormas. ${ }^{21}$ Meski demikian, Kemendagri mengalami dilema karena tidak dapat membubarkan ormas ini di tingkat daerah. Hal ini dikarenakan terbitnya putusan Mahkamah Konstitusi (MK) Nomor 82/PUU-XI/2013 yang menyatakan bahwa organisasi yang tidak memiliki badan

17 Pihak Kesbangpol Pemkot Surakarta tidak bersedia memperpanjang SKT Gafatar di Surakarta dikarenakan ada surat edaran dari Kesbangpol Pusat yang menyatakan bahwa Gafatar terindikasi sebaga salah satu Ormas yang terlarang. Lihat http://www.republika.co.id/berita/ nasional/umum/16/01/13/o0vjf2354-gafatar-sempat-terdaftar-sebagai-ormas-resmi-di-pemkot-surakarta (diakses 12 Februari 2016).

18 Kepala Kesbangpol Kabupaten Banyumas, Setyo Rahendra mengatakan bahwa Gafatar terdaftar sebagai ormas di Banyumas sejak tahun 2012 dan berakhir hingga 31 Desember 2015. http://nasional.republika.co.id/berita/nasional/umum/16/01/13/o0vxnb383-ternyata-gafatar-pernahterdaftar-resmi-sebagai-ormas-di-banyumas (diakses 13 februari 2016).

${ }^{19}$ Kepala Kesbangpol Balikpapan, Astani menyatakan bahwa sejak 2012, Gafatar yang terdaftar di Kebangpol Balikpapan sudah memiliki akta notaris, kepengurusan, dan memiliki sekitar 50 anggota aktif. http://www.mediaindonesia.com/news/read/25108/gafatar-sudah-terdaftar-di-balikpapan-sejak-2012/2016- 0116 (diakses 13 Februari 2016).

20 Sebagaimana yang dipublikasikan oleh situs Kemandagri pada 13 Januari 2016, Menteri Dalam Negeri Tjahjo Kumolo menyatakanbahwa Gafatarmerupakanorganiasasiyangtidaktercatatkandi Kemendagri sebagai organisasi masa. http://setkab.go.id/gafatar-tidak-tercatat-sebagai-ormas-dikemendagri/ (diakses 9 Februari 2016).

${ }^{21}$ Kemendagri mengeluarkan Surat Ditjen Kesbangpol Kementerian Dalam Negeri RI Nomor 220/3657/D/III/2012 tanggal 20 November 2012 yang menyatakan Gafatar sebagai Organisasi Terlarang. 


\section{ART IKEL}

hukum, (termasuk pula Gafatar) dapat mendaftarkan diri kepada instansi pemerintah yang bertanggung jawab dan harus diakui secara daerah maupun nasional. Surat izin ormas itu berlaku hinggalima tahun.

Sangat disayangkan ketika pemerintah tidak mengambil sikap tegas untuk membubarkan Gafatar pada saat itu. Padahal, pemerintah sebenarnya bisa membubarkan ormas ini dengan alasan lain, misalnya meresahkan masyarakat dan menyebarkan ajaran yang menyimpang dari Islam. Selain itu, pemerintah juga bisa membubarkan Gafatar dengan menggunakan dasar pertimbangan dari Putusan Pengadilan Negeri Jakarta Selatan dan fatwa MUI yang menyatakan bahwa ajaran Ahmad Musaddeq adalah sesat, baik al-Qiyadah al-Islamiyah, Komar, termasuk Gafatar.

\section{Rekrutmen Anggota}

Hijrahnya anggota-anggota Gafatar ke Kalimantan tidak lepas dari adanya perekrutan anggota dan indoktrinasi yang mampu meyakinkan anggota kelompok ini untuk melakukan hijrah. Perekrutan anggota Gafatar umumnya dilakukan melalui kegiatan-kegiatan yang mengusung tema sosial seperti bakti sosial, donor darah, dan gotong royong. cara ini terbukti cukup efektif menarik simpati masyarakat sebelum akhirnya mereka melakukan indoktrinasi ajaran Gafatar kepada para anggotanya.

Hasil penelitian IMCC bekerjasama dengan PPIM UIN Jakarta menunjukkan bahwa orang-orang yang tertarik dan bergabung dengan Gafatar karena mengetahui atau diajak orang terdekat seperti teman, saudara atau guru. Banyak dari anggota Gafatar, menurut riset ini, adalah mantan anggota NII KW 9 yang kecewa dengan model kepemimpinan Panji Gumilang. Kemudian ketika diajak bergabung dengan Gafatar yang mana Ahmad Mushadeq juga menjadi seorang tokoh spritualnya, mereka 


\section{ART IKEL}

ikut bergabung. Adapun sebagian lainnya tertarik bergabung karena adanya program ketahanan pangan yang menjadi salah satu misi utama Gafatar. ${ }^{22}$

Rata-rata pengikut Gafatar yang berhasil diwawancai oleh tim IMCC menyatakan bahwa mereka tidak ada yang kecewa terhadap Gafatar. Secara umum, mereka kecewa terhadap kebijakan pemerintah yang mengevakuasi mereka dari Kalimantan. Suparta, salah satu anggota Gafatar yang sudah setahun lebih tinggal bersama komunitas Gafatar di Kalimantan Barat, mengatakan bahwa kehidupannya secara ekonomi dan sosial jauh lebih baik ketimbang sebelum menjadi anggota Gafatar. Di sana dia berhasil membangun usaha peternakan yang mengalami perbaikan dan peningkatan. Anggota lainnya, Agus Supriyadi, mengatakan bahwa tidak ada yang salah dalam Gafatar karena Gafatar tidak anti dengan Pancasila. Selain itu, kampanye kegiatannya hanya seputar ketahanan pangan yang menurut Agus, justru membantu pemerintah Indonesia. ${ }^{23}$

Secara kelembagaan, peneliti melihat bahwa Gafatar secara umum memiliki perbedaan mendasar dari organisasi sebelumnya yaitu Al-Qiyadah Al-Iskamiyah dan Komar. Tumanurung, sebagai tokoh penting Gafatar, mengubah cara perekrutan dengan menggunakan cara menarik simpati melalui kegiatan sosial, dan propaganda merangkul kebersamaan tanpa membeda-bedakan ras, suku, dan agama. Pola perekrutan model NII yang dahulu digunakan oleh Musaddeq dengan cara sembunyisembunyi dan tertutup, kini diubah dengan cara baru yang bersifat terbuka dan dapat diakses banyak orang melalui ormas Gafatar. ${ }^{24}$ Akan tetapi, jika dilihat dari perjalanan

${ }^{22}$ Robi Sugara, "Rehabilitasi Korban..., hlm. 5-35.

${ }^{23}$ Ibid.

24 http://portalsatu.com/berita/eks-paspampres-nii-kw-9-berbagi-kisah-soal-teknikperekrutan-gafatar-5069 (diakses 17 Maret 2016). 


\section{ART IKEL}

Musaddek, bukan tidak mungkin dia juga mengajarkan ajarannya sebagaimana yang terjadi dalam Al-Qiyadah Al-Islamiyah dan Millah Abraham. Pendapat inilah yang kemudian menjadi landasan bagi MUI dan Kemendagri untuk memberikan legitimasi kepada Gafatar sebagai organisasi sesat dan harus dibubarkan.

\section{Konsep Hijrah Gafatar}

Musadeq menyampaikan inti ajaran Millah Abraham yang mengajak setiap penganutnya menganut ajaran Ibrahim. Musadeq berpandangan bahwa Muhammad SAW bukanlah nabi terakhir atau penutup kenabian. Menurutnya, tugas kenabian Muhammad dianggap selesai setelah hancurnya peradaban Islam pasca Perang Salib pada abad ke-13. Oleh karena itu, pengikutnya diajak berjuang menegakkan kembali norma agama $(d i n)$. Mereka meyakini adanya fase perjuangan, yakni tahap penanaman akidah sehingga tidak diperlukan ibadah. Ibadah salat dan puasa Ramadan tidak dibutuhkan. Konsep ibadah itu hanya ada dalam agama, sedangkan yang diperlukan saat ini adalah perjuangan untuk din (agama) dan menegakkan aturan manusia secara holistik. Tugas pengikutnya hanyalah membangun peradaban baru yang sama tatkala Ibrahim diutus ke bumi. Ajaran Millah Abraham meyakini peradaban agama baru ini akan lahir melalui sejumlah tahapan yaitu dakwah sembunyi-sembunyi (sirr), terbuka (jahron), pindah lokasi (bijrah), perang (qital), puncak berdakwah (fathu makkah), dan eksis di dunia (madinatul munawwaroh). ${ }^{25}$

Fase pertama yaitu dakwah sirri, yakni keyakinan didakwahkan secara sembunyi-sembunyi. Pada fase selanjutnya yaitu dakwah secara terbuka (jihar, jahrun) yang dilakukan 2007. Tahun 2014 diyakininya sebagai fase diperlakukan buruk oleh

${ }^{25}$ Moch. Rosyid, “Tanggung Jawab Pemerintah”, hlm. 100. 
penguasa. Fase berikutnya hijrah (pindah), yaitu dalam hal ini Mempawah menjadi lokasi hijrah mereka. Fase berikutnya yaitu qital (perang), mendapatkan kemenangan (futub), dan mendirikan Negara Islam (khilafah). ${ }^{26}$

Sebagaimana dinyatakan Rosyid, perekrutan pengikut Gafatar dilakukan dengan mengadakan mitsaq sebagai tanda kesediaan untuk berhijrah menjadi muslim dan bergabung dalam Al-Qiyadah Al-Islamiyah. Dakwahnya dilakukan dengan interaksi personal dalam bentuk diskusi dan dialog yang selanjutnya mengajak untuk mengkaji Al-Quran guna mencari solusi berbagai persoalan pribadi maupun sosial. Ajaran Millah Abraham merupakan hasil gabungan antara Al-Quran dengan Injil. Kelahirannya untuk menyatukan agama-agama Ibrahim yang ada di dunia yakni Yahudi, Islam, dan Nasrani.

\section{Ideologi Mesianis Gafatar}

Munculnya Gafatar dengan tokoh sentral Ahmad Musaddeq sebenarnya merupakan wujud dari fenomena mesianis kontemporer. Musaddeq menganggap bahwa dirinya merupakan seorang pembawa risalah Tuhan di akhir zaman yang akan menyelamatkan umat manusia setelah bertapa di Gunung Bunder Bogor pada 2006. ${ }^{27}$ Mesianisme sendirimerupakan paham yang menganggap bahwa akan hadir seorang pemimpin akhir zaman, yang dianggap sebagai juru selamat yang akan membawa kebaikan dan pembaruan ke arah yang lebih baik di kala terjadi ketertindasan suatu kaum. Munculnya fenomena Gafatar ini bisa dikatakan serupa dengan munculnya gerakangerakan lain yang sama-sama mengaku membawa seorang pemimpin sebagai juru

\footnotetext{
26 Ibid.

${ }^{27}$ Robi Sugara, "Rehabilitasi Korban..., hlm. 18.
} 
selamat yang mereka sebut Imam Mahdi, al-Masih, atau Ratu Adil menurut versi mereka. Dengan demikian, dapat dikatakan bahwa pemahaman terhadap juru selamat versi Gafatar bisa dikategorikan sebagai pemahaman mesianisme kontemporer.

Mesianisme klasik sebenarnya sudah banyak diketahui banyak orang dengan merujuk pada ajaran-ajaran mainstream agama besar yang intinya menyatakan bahwa akan datang seorang juru selamat yang akan membawa dan menuntun ke arah kebaikan. Di masa lampau kehadiran mesianisme tidak sampai membuat heboh masyarakat, karena masyarakat meyakini mesianisme sesuai dengan ajaran agama-agama besar yang mereka anut. Tentu saja mesianisme paham keagamaan yang tidak memiliki orientasi politik praktis, maupun kepentingan sepihak, melainkan tujuan untuk mengentaskan ketertindasan. Mesianisme sendiri merupakan sebuah doktrin penantian akan kedatangan sang juru selamat yang diyakini bakal membebaskan suatu bangsa dari belenggu penjajahan. Secara harfiah, Mesianisme berasal kata Mesiah (bahasa Ibrani) yang artinya hampir sepadan dengan makna kata al-masih dalam bahasa Arab yakni yang diusap, diurapi, atau diurut. ${ }^{28}$ Makna diusap dalam artian diusap menggunakan minyak seperti prosesi pengangkatan pemimpin keagamaan. Doktrin Mesianisme ini sudah berusia kurang lebih 3000 tahun yang merupakan warisan dari tradisi bangsa Yahudi dari keturunan Nabi Ibrahim. ${ }^{29}$

Jika dilihat secara psikologis dan sosiologis, doktrin Mesianisme merupakan luapan ekspresi keputusasaan suatu bangsa yang selalu ditindas oleh bangsa-bangsa lain. Dalam keterputusasaanitu terselip sebuah harapan akan datangnya juru selamatyang

28 http://suaramuhammadiyah.com/khazanah/hadlarah/2016/02/16/sejarah-mesianisme/ (diakses 28Februari 2016).

${ }^{29}$ Ahmad Suhelmi, Negara dan kekuasaan dalam Pemikiran Politik kristiani, dalam Pemikiran Politik Barat, cetakan ke-3, (Jakarta, Gramedia Pustaka Utama, 2007), hlm. 55. 
akan membawa mereka kepada kehidupan yang merdeka. ${ }^{30}$ Pemahaman Mesianisme kemudian berkembang menjadi keyakinan teologis hingga saat ini masih tetap kokoh bertahan. Keyakinan mesianisme menjadi bagian pokok dalam ajaran Yahudi dan Nasrani. ${ }^{31}$ Sementara dalam konteks ajaran Islam, konsep mesianisme juga berkembang namun tidak seperti konsep agama Yahudi dan Nasrani.

Dalam doktrin Islam memang dikenal konsep al-Masih dan Imam Mahdi. Kedua konsep ini memang masih menjadi perdebatan di kalangan ulama, khususnya tentang Imam Mahdi. Adapun konsep al-Masih, menurut keyakinan umat Islam, hanya ditujukan kepada sosok Nabi Isa 'alaibis salam. Dalam Al-Qur'an, setiap kali menyebut nama Nabi Isa biasanya diikuti dengan penyebutan julukan ini, yakni al-Masih. Tentu saja keyakinan semacam ini cukup berbeda dengan tradisi Yahudi yang lebih luas cakupan pemahaman tentang sang Mesiah yang lebih menekankan pada kebangkitan psiko-sosiologis. Adapun mengenai sosok Imam Mahdi dalam Islam, konon bakal datang bersamaan dengan kebangkitan kembali Nabi Isa al-Masih pada detik- detik akhir zaman yang subtansinya hampir mirip dengan doktrin Mesianisme pada umumnya. Islam mengajarkan bahwa konsep Imam Mahdi berperan sebagai pemimpin akhir zaman dalam menyelamatkan keadaan kaumnya demi mengajak kembali ke jalan agama yang benar dan meluruskan ajaran yang dianggap menyimpang. Jika kedatangan sang Mesiah, dalam tradisi Yahudi, dan Nasrani mengandung makna psikologis dan

${ }^{30}$ Martin Kavka, Jewish Messianism and the Historyof Philosophy, (Cambridge: Cambridge University Press, 2004), hlm.7.

31 Messiah merupakan doktrin tentang kedatangan seorang penebus yang disambut sebagai pahlawan dan pembangun dengan karakter yang khas, pembangunan itu tidak hanya memengaruhi pemikiran agama di Barat tetapi juga memberikan inspirasi dalam gerakan sekular modern. Lihat, $H$. Kohn, Messianism, dalam Edwin R.A. Seligman (ed.) Encyclopediaof the Social Sciences, (New York: The MacmullanCompany, 1959), hlm. 356. 
sosiologis secara umum, maka konsep Imam Mahdi dalam tradisi Islam, lebih mengarah pada konteks teologis yang berkaitan dengan pemimpin agama. ${ }^{32}$

Dalam konteks sejarah Indonesia, di masyarakat Jawa juga mengenal konsep mesianisme yang lebih dikenal dengan istilah Ratu Adil atau Satria Piningit. ${ }^{33}$ Seperti halnya bangsa Yahudi yang berkali-kali ditindas oleh bangsa lain, bangsa Indonesia yang pernah dijajah oleh bangsa lain selama berabad-abad hingga akhirnya mengenal konsep ini. Dalam situasi terjajah, kondisi tersebut membawa kepada psikologi keterputusasaan. Di tengah rasa putus asa itulah orang-orang Jawa mengharapkan datangannya Sang Pemimpin yang akan membebaskan mereka dari penjajahan. Dengan demikian, sekalipun menggunakan terminologi yang berbeda-beda, konsep al-Masih, Imam Mahdi, Ratu Adil, atau Satria Piningit, semuanya memiliki kesamaan visi dan konteks dengan mesianisme. Visinya menghendaki penyelamatan, dan konteksnya berupa situasi tertindas yang dialami oleh suatu kelompok atau bangsa. ${ }^{34}$

Mesianisme klasik umumnya tidak memiliki tujuan politik praktis, dan hanya bertujuan untuk misi penyelamatan kaum yang tertindas. Kini mesianisme kontemporer muncul dengan bentuk yang berbeda. Mesianisme kontemporer hadir disertai dengan kamuflasegerakan-gerakan sosial, ekonomi, dan kemasyarakatan sehingga terlihat samar. Gerakan-gerakan yang mengusung konsep mesianisme kontemporer biasanya tidak bisa lepas dari konsep ajaran dan doktrin yang mirip seperti sebuah ajaran agama baru.

32 M. Bucaille, Bibel, Qor'an and Sains Modern, Alih bahasa; HM. Rasjidi, (Jakarta: Bulan Bintang, 1978), hlm. 154.

${ }_{33}$ Dalam hal ini Cokroaminoto, pemimpin Sarekat Islam (SI), pernah dianggap sebagai satria piningit, Mesias, Ratu Adil, dan Heru Cakra oleh masyarakat Indonesia terutama pendukung SI. Lihat, Iswara N. Raditya, "Tjocroaminoto: Ratu Adil, Mesias, dan Titisan Dewa Wisnu" dalam https://tirto.id/tjokroaminoto-ratu-adil-mesias-dan-titisan-dewa-wisnu-czH9, diakses 21 November 2019. Lihat juga, Denis Lombard, Nusa Jawa: Warisan Kerajaan-Kerajaan Konsentris (Jakarta: Gramedia, 2005), hlm. 166-167.

${ }^{34}$ E. Fromm, Revolusi Harapan, (Yogyakarta: Pustaka Pelajar, 1999), hlm. 17. 
Sehingga tidak jarang jika gerakan mesianisme kontemporer juga selalu mengajarkan agama baru dengan mengusung keyakinan mesianistik versi mereka. ${ }^{35}$ Bahkan tidak jarang pula mesianisme kontemporer diiringi dengan tujuan politik ekstrim tertentu seperti mendirikan sebuah negara. Inilah yang membedakan mesianismeklasikdengan mesianisme kontemporeryang dianggap berbahaya karena salah satu tujuan akhir mereka adalah ingin mendirikan negara mesianis. Gafatar muncul dengan mengusung paham mesianisme yang mengusung Ahmad Musaddeq sebagai Imam Mahdi atau Ratu Adil mereka dengan berkamuflase sebagai sebuah organisasi masa yang bergerak pada kegiatan sosial, ekonomi, kemasyarakatan. Gafatarmuncul diawali oleh rasa kekecewaan Ahmad Musaddeq terhadap kepemimpinan NII KW-IX. Ia juga merasa tidak puas terhadap pemerintahan saat ini. Sehingga tidak jarang propaganda Gafatar berupaya untuk memberikan citra yang selalu buruk terhadap pemerintah demi menggerakkan masa perlawanan hingga akhirnya membentuk kelompok Gafatar untuk merekrut anggota sebanyak banyaknya. Apabila dilacak lebih jauh ternyata Gafatar memiliki agenda untuk mengajarakan dan menyebarkan paham agama baru mereka dalam rangka untuk mewujudkan Negara Karunia Tuan Semesta Alam (NKSA). Inilah salah satu bukti bahwa Gafatar merupakan salah satu bentuk mesianisme kontemporer yang muncul akhir-akhir ini.

\section{Siklus Krisis dan Ancaman Terhadap NKRI}

Adanya fenomena Gafatar menunjukkan bahwa Indonesia masih memiliki problem terkait krisis ideologi yang harus segera diselesaikan. Dari gejala hijrah dan konsep ideologi mesianis Gafatar sangat dimungkinkan Gafatar memiliki visi

${ }^{35}$ Suara Muhammadiyah, Gafatar dan bahaya Mesianisme, hlm. 10-11. 
mendirikan sebuah negara baru dengan aturan dan hukum yang sesuai dengan keyakinan mereka. Misi tersebut berpotensi menimbulkan gerakan separatisme yang mengancam disintegrasi bangsa dan berpotensi menimbulkan konflik di dalam negeri. Ancaman-ancaman tersebut adalah ancaman nyata dari dalam negeri yang menjadi ancaman potensial (laten) yang serius terhadap kedaulatan NKRI. ${ }^{36}$ Maka perlu adanya tindakan prenventif yang humanis, selain penanganan hukum terhadap kasus ini. Selain itu, perlu juga adanya pembinaan agar kembali ke pemahaman yang lurus agar tidak terjerumus di kemudian hari.

Keadaan krisis ideologi yang muncul di masyarakat akhir-akhir ini bisa jadi disebabkan karena kurangnya peran pemerintah dan seluruh elemen masyarakat dalam memperkenalkan dan menanamkan ideologi negara, yakni Pancasila, dan nilai-nilai agama secara maksimal (Rahman, 2018). Kondisi semacam ini kemudian dimanfaatkan oleh Gafatar, dan organisasi lainnya, untuk masuk dan menanaman paham mereka yang bertentangan dengan nilai-nilai Pancasila.

Fenomena krisis ideologi di atas menandakan bahwa bangsa Indonesia sedang mengalami kondisi yang rawan dimasuki ideologi asing seperti ideologi fundamnetalis yang dibawa oleh para kelompok garis keras maupun ideologi menyimpang seperti yang dibawa oleh Ahmad Musaddeq. Bukan tidak mungkin orang yang frustasi secara ideologi akan mengambil jalan pintas dengan mengikuti ideologi yang menurutnya sesuai. Hanya saja ideologi asing tersebut kebanyakan malah mengarah kepada disintegrasi bangsa dan mengancam kedaulatan NKRI. ${ }^{37}$ Aksi pembakaran di kamp

36 A. Gani Jusuf, Konsepsi Ketahanan Nasional dalam Pengembangan Kualitas Materi Pancasila dan Kewarganegaraan, Jurnal Sosioteknologi, Edisi 13 Tahun 7, April 2008, hlm. 393-394.

${ }_{37}$ Disintegrasi bangsa dimaknai sebagai perpecahan kesatuan bangsa yang mengarah pada konflik-konflik dalam negeri. Disintegrasi bangsa bisa mengarah kepada tindakan makar seperti tindakan separatis, teroris, dan tindakan anarkis lain yang mengancam kedaulatan NKRI. 


\section{ART IKEL}

\section{E-ISSN: $2615-5028$}

Gafatar di Mempawah adalah sebuah fenomena puncak dari kekesalan warga yang tentu hal ini merugikan semuapihak. Disatu sisi, pihak Gafatar merasa menjadi korban, namun di sisi lain, pihak warga pun mengkalim merasa diresahkan dengan keberadaan Gafatar. Kerusuhan inilah yang dimaksud sebagai upaya disintegragi bangsa dalam bentuk kerusuhan dalam negeri. Begitu pula visi Gafatar yang memimpikan mewujudkan negara dalam sebuah negara yang mereka sebut sebagai Negara Karunia Tuan Semesta Alam (NKSA). Bisa saja jika Gafatar dibiarkan, maka akan menimbulkan potensi perpecahan dan tindakan makar terhadap pemerintahan yang sah.

Penanganan kasus Gafatar melalui jalur hukum seharusnya sesuai dengan tujuan hukum itu sendiri, yakni tidak hanya menimbulkan efek jera si pelaku, ${ }^{38}$ tetapi juga mampu menjaga ketentraman dan keamanan yang kondusif bagi semua pihak. ${ }^{39} \mathrm{Hal}$ ini demi menjamin perlindungan masyarakat dari tindakan kejahatan (social defence) dan upaya mencapai kesejahteraan masyarakat (social welfare). ${ }^{40}$ Penanganan hukum pidana mengenai delik-delik agama dengan cara melaporkan kepada pihak yang berwenang seharusnya menjadi acuan hukum yang rasional dari masyarakat dalam menanggulangi kejahatan, ${ }^{41}$ bukan dengan aksi main hakim sendiri. Seharusnya para penegak hukum, baik kepolisian maupun hakim mampu bersikap tanggap dengan mempergunakan hukum yang terbaik dalam keadaan yang paling buruk sekalipun seperti dalam menangani kasus penyimpangan agama yang dilakukan Gafatar ini. Peran edukasi dari

38 T. Mathiesen, "General Prevention as Communication". Dalam RA. Duff and David Garland, A Reader on Punishment, (New York: Oxford University Press Inc., 1995), hlm. 225.

39 Mahmud Mulyadi, Revitalisasi Alas Filosofis Tujuan Pemidanaan dalam Penegakan Hukum Pidana di Indonesia. (Medan: USU Repository, 2006), hlm 9.

40 Barda Nawawi Arief, Bunga Rampai Kebijakan Hukum Pidana, (Bandung: Citra Aditya Bakti, 2002), hlm. 2.

${ }^{41}$ Sudarto, Hukum dan Hukum Pidana, (Bandung: Alumni, 1996), hlm. 38. 


\section{ART IKEL}

para penegak hukum juga diperlukan untuk membangun masyarakat yang sadar hukum demi mencegah aksi main hakim sendiri.

Pemerintah jangan berhenti pada penganganan hukum semata, namun perlu diiringi dengan upaya pembinaan ideologi dan paham keagamaan bagi eks anggota Gafatar setelah ormas itu dibubarkan. Penanganan dan pembinaan para eks Gafataryang kembalikedaerah asal juga harus menjadi prioritas agar kedepannya tidak lagi menganut ideologi yang serupa, dan kembali kepada pemahaman yang benar baik secara ideologi bangsa maupun ideologi mainstream agamanya masing-masing. Dengan menggunakan penanganan jalur hukum dan pembinaan tersebut, penanganan Gafatar bisa diatasi secara komprehensif, tidak hanya pembubaran semata namun juga pembinaan keyakinan agar kelak tidak muncul organisasi menyimpang yang serupa.

Pemerintah harus belajar dari kasus penanganan al-Qiyadah al-Islamiyah yang hanya menggunakan penanganan hukum dengan menekankan pembubaran dan pemidanaan bagi para pengurusnya. Di kemudian hari muncul komunitas Millah Abraham (Komar) yang pengurusnya adalah Ahmad Musaddeq dan pengikutnya yang merupakan eks anggota al-Qiyadah al-Islamiyah. Bahkan sekalipun Komar dibubarkan, tetap saja mereka melanjutkan kegiatannya dengan membentuk Gafatar. Hal ini menunjukkan bahwa penanganan melalui jalur hukum saja dirasa kurang memberikan efek jera. Bukan tidak mungkin meskipun Gafatar sudah dinyatakan sesat oleh MUI dan dibubarkan, namun di kemudian hari pemahaman yang serupa akan muncul kembali. Maka dari itu, perlu adanya pembinaan moral dan keyakinan keagamaan bagi para eks anggota Gafatar agar mereka tidak membuat kegiatan yang serupa di kemudian hari. Di sinilah seharusnya pemerintah dan para tokoh agamawan berperan aktif mengedukasi 


\section{ART IKEL}

dan meluruskan kembali keyakinan keagamaan mereka sesuai keyakinan agama masingmasing dengan menggunakan pendekatan resolusi konflik yang humanis. ${ }^{42}$

Bentuk resolusi konflik yang humanis dengan mengkedepankan pendekatan kultural dengan solusi psikologis ini dapat dilakukan dengan penyampaian agama yang sejuk, sehingga dapat menyadarkan seseorang dalam kesesatannya. Resolusi ini juga bermanfaat memberikan efek preventif, yakni mencegah seseorang berbuat ataupun mengikuti ajaran sesat. Upaya preventif melalui pencerahan kepada masyarakat tentang bentuk dan bahaya ajaran yang menyimpang, akan menjadikan masyarakat berhati-hati dalam menerima ajaran yang masih diragukan kebenarannya. Dari hal tersebut dapat dikatakanbahwa resolusikonflikyanghumanis merupakan salah satu solusi yang tepat dalam menangani kasus penyimpangan keyakinan seperti Gafatar yang harapannya mampu menangani secara komprehensif, tidak hanya melalui jalur hukum semata, melainkan juga melalui pendekatan kultural, moral, dan pendidikan agama masingmasing. Dengan demikian harapannya masyarakat akan tercerahkan dan tidak akan mudah terhasut oleh pemahaman-pemahaman yang menyimpang dari ajaran mainstream agama pada umumnya.

\section{KESIMPULAN}

Gafatar merupakan salah satu organisasi sosial yang berhasil merekrut dan memonilisasi ribuan orang untuk hijrah ke Mempawah, Kalimantan Barat. Dari anggota yang direkrut diketahui bahwa mereka mayoritas berasal dari mantan anggota NII KW-9 dan masyarakat yang terpesona dengan program ketahanan pangan yang menjadi salah satu misi Gafatar. Gafatar juga bermuatan ideologis karena akar dari

42 Thoha Hamim, Resolusi Konflik Islam Indonesia, (Yogyakarta: LKiSPelangi Aksara, 2007), hlm. 65. 


\section{ART IKEL}

gerakan ini adalah Al-Qiyadah Al-Islamiyah dan Komunitas Millah Abraham. Dalam beberapa gerakan sebelumnya, Ahmad Musaddeq menyebut dirinya sebagai Imam Mahdi bahkan Nabi. Gerakan ini juga disebut sebagai gerakan politik karena bertujuan mendirikan Negara Kesatuan Tuan Semesta Alam (NKSA). Komunitas Gafatar yang tinggal di Mempawah Kalimantan Barat dimungkinkan merupakan prototype dari NKSA tersebut. Berbagai upaya pimpinan Gafatar untuk menyembunyikan jati-diri dan ideologi Gafatar menjadi sekedar gerakan sosial tercium dengan jelas oleh aparat pemerintah.

Propaganda Gafatar terkait dengan kondisi sosial-politik yang buruk seperti kesenjangan sosial, korupsi, dan penegakan hukum yang tidak adil untuk menciptakan sugesti pesimistis bahwa bangsa ini sudah rusak sehingga perlu ideologi baru untuk memperbaikinya. Sugesti pesimistis menjadi cara ampuh Gafatar untuk merekrut dan mengindoktrinasi para calon pengikut yang mengalami kegelisahan ideologi dan juga pemahaman agama yang lemah sehingga mudah disusupi ideologi baru. Hal tersebut memperkuat pandangan bahwa Gafatar memanfaatkan siklus krisis ideologi yang sering terjadi di masyarakat dengan menawarkan sebuah ideologi baru yang menawarkan janji-janji kebahagiaan dan kesejahteraan secara instan. Dari fenomena siklus krisis ideologi tersebut, seharusnya segera ditanggulangi oleh pemerintah dan para tokoh agamawan tanggap dengan berperan aktif mengambil langkah yang tepat. Penegakkan secara hukum harus dibarengi dengan pembinaan ideologi melalui pendekatan resolusi konflik yang humanis agar mereka yang terlanjur dalam kesesatan mau kembali kepada keyakinan yang benar. Peran aktif agamawan juga diperlukan dalam memberikan pencerdasan kepada masyarakat luas sebagai upaya preventif agak tidak mengikuti ideologi yang menyesatkan. 


\section{ARTIKEL}

\section{DAFTAR PUSTAKA}

\section{A. Buku \& Artikel}

Al Makin, Nabi-Nabi Nusantara: Kisah Lia Eden dan Lainnya (Yogyakarta: Suka Press, 2017.

Arief, Barda Nawawi,Bunga Rampai Kebijakan Hukum Pidana, Bandung: Citra Aditya Bakti, 2002.

Bucaille, M., Bibel, Qor'an and Sains Modern, Alih bahasa; HM. Rasjidi, Jakarta: Bulan Bintang, 1978.

Fromm, Eric., Revolusi Harapan, Yogyakarta: Pustaka Pelajar, 1999.

Hamim, Thoha, Resolusi Konflik Islam Indonesia, Yogyakarta: LkiS Pelangi Aksara, 2007.

Jusuf, A. Gani, Konsepsi Ketahanan Nasional dalam Pengembangan Kualitas Materi Pancasila dan Kewarganegaraan, Jurnal Sosioteknologi, Edisi 13 Tahun 7, April 2008.

Kavka, Martin, Jewish Messianism and the Historyof Philosophy, Cambridge: Cambridge University Press, 2004.

Kohn, H., Messianism, dalam Edwin R.A. Seligman (ed.) Encyclopedia of the Social Sciences, New York: The MacMillan Company, 1959.

Mathiesen, T., “GeneralPrevention as Communication”. Dalam RA. Duff and David Garland, A Reader on Punishment, New York: Oxford University Press Inc., 1995.

Mulyadi, Mahmud, Revitalisasi Alas Filosofis Tujuan Pemidanaan dalam Penegakan Hukum Pidana di Indonesia. Medan: USU Repository, 2006.

Sudarto,HukumdanHukumPidana,Bandung: Alumni,1996. 
Sugara, Robi, "Rehabilitasi Korban: Belajar dari Mantan Aktivis NII, Gafatar dan Deportan/Returni ISIS” Convey Report Vol. 1, No. 6,. Jakarta: IMCC, 2018.

Rahardjo, Satjipto, Membedah Hukum Progresif, Jakarta: Kompas, 2006.

Rahman, M. Taufiq, Pengantar Filsafat Sosial, Bandung: Lekkas, 2018.

Suhelmi, Ahmad, Negara dan kekuasaan dalam Pemikiran Politik kristiani, dalam Pemikiran Politik Barat, cetakan ke-3, Jakarta, Gramedia Pustaka Utama, 2007.

Tempo, Janji Anggota Gafatar Terungkap, edisi Rabu, 13 Januari 2016.

Yogaswara, A., Maulana Ahmad Jalidu, Aliran Sesat dan Nabi-nabi Palsu, Yogyakarta: Narasi, 2008.

Zara, M. Yuanda, Aliran-aliran Sesat di Indonesia, Yogyakarta: Banyu Media, 2007.

\section{B. Media Massa}

Gatra, 27 Januari 2016.

Gatra, 27 Januari 2016.

Gatra, 16 Januari 2016. http://m.jpnn.com

http://nasional.kompas.com

http:// nasional.news.viva.co.id

http:// nasional.republika.co.id

http://setkab.go.id

http:/ / suaramuhammadiyah.com

http://www.antaranews.com

http://www.beritasatu.com 
ART IKEL

E-ISSN: 2615-5028

http://www.beritasatu.com

http://www.beritasatu.com

http://www.cnnindonesia.com

http://www.kemendagri.go.id

http://www.mediaindonesia.com

http://www.republika.co.id

https://m.tempo.com

Suara Mubammadiyah, No. 4/101, 16-29 Januari 2016. 